\title{
ANALYSIS OF MHD EFFECT ON RAYLEIGH STEP SLIDER BEARING LUBRICATED WITH COUPLE-STRESS FLUIDS
}

\author{
AYYAPPA G. HIREMATH ${ }^{1}$, HANUMAGOWDA B. N. ${ }^{2}$, BIRADAR KASHINATH ${ }^{3}$ \& DHANRAJ NEELA ${ }^{4}$ \\ ${ }^{1}$ Department of Mathematics, Poojya Doddappa Appa College of Engineering, Kalaburagi, Karnataka, India \\ ${ }^{2}$ Department of Mathematics, School of Applied Sciences, REVA University, Karnataka, India \\ ${ }^{3}$ Department of Mathematics, Govt. Degree College Aland, Karnataka, India
}

${ }^{4}$ Department of Mathematics, Faculty of Engineering and Technology, Sharnbasva University, Kalaburagi, Karnataka, India

ABSTRACT: The magneto-hydrodynamic Rayleigh step slider bearing lubricated with couple-stress fluids is analyzed
under transverse magnetic field. The expression for non-dimensional pressure, non-dimensional load carrying capacity,
frictional force and the co-efficient of friction is derived and results are discussed for various non-dimensional
parameters. It is observed that the effect of Hartmann number and couple-stress parameter enhances the load carrying
capacity, frictional force and the co-efficient of friction.
KEYWORDS: Couple Stress, Magneto Hydrodynamics \& Rayleigh Step Bearing

Received: Jun 06, 2020; Accepted: Jun 26, 2020; Published: Aug 24, 2020; Paper Id.: IJMPERDJUN2020860

\section{INTRODUCTION}

The analysis of interface of conducting fluids with electromagnetic occurrences is called Magnetohydrodynamic (MHD). MHD lubrication is significantly than hydrodynamic lubrication, because most MHD bearing models have been developed from the perspective of mathematical analysis simplicity rather than practicality. The unexpected variation in the viscosity of lubricants with temperature, made the use of an electrically conducting fluid more popular. The first author to represent a study of MHD infinite inclined plane slider bearing in the existence of uniform transverse magnetic field was Snyder [1] and found that a significant increase in load capacity was possible with liquid metal lubricants in the presence of magnetic field. Shukla [2] examined optimum load of MHD slider bearing using film thickness and conductivity functions as bounded control variables and concluded that if the conductivity of bearing surface is of step-type in nature, it is more desirable for a uniformly distributed magnetic field. Hughes [3] analysed the MHD finite step slider bearing in the presence of magneticfield applied both tangentially and transversely to the fluid film. For the transverse field it is found that only a slight increase in pressurization can be affected on open circuit conditions and that short circuit conditions are unfavorable. Anwar [4] analysed the MHD characteristic of inclined slider bearing with arbitrary magnetic field. It is found that a nonuniform applied magneticfield gives higher load capacity as compared with uniform magnetic fields.

In 1918, Lord Rayleigh discovered a film geometry where a step is split the lubricant film into two zones viz; $h_{1}$ at the entry zone and $h_{2}$ at the exit zone and result holds good when the viscosity of lubricant is considered as function of pressure. Many researchers have been studied the characteristics of the Rayleigh step bearing lubricated with non-Newtonian fluids to name few are Jianming and Gaobing [5], and Naduvinamani and Siddangouda [6] have studied the effect of couple stress on the characteristics of Rayleigh step bearings.

The slider bearings have practical applications in machine design and in other kinds of machine elements in 
which rectilinear sliding motions occur. The thrust area of the step bearings is in the clutch plate, gear box, thrust bearings and journal bearings etc. Awareness of the features of bearing is important when taking into consideration specific operational circumstances. Several analyses on lubrication performance of slider bearings have been concluded in the last few years. Later to upgrade the lubricating performance the increased utilization of Newtonian lubricant which has been blended with long chain polymers has been observed. Using additives stabilizes the flow properties and minimizes lubricant sensitivity to change shear rate. A variety of micro-continuum theories have been carried out, but Stokes [7] theory is the simplest micro-continuum theory which allows the existence of Couple stresses and body couples. The load carrying capability, force of friction increases, and frictional coefficient decreases for a slider bearing greased with couplestress fluid was concluded by Ramanaiah and Sarkar [8]. A relative study is made between parabolic and inclined slider lubricated with couplestress fluid by Moobalaji and John [9] and found that parabolic slider has more superior load carrying capability than inclined slider. The rough slider bearing with couple stress was analyzed by Naduvianamani et al [10]. Buzurke et al [11] examined the porous step slider with couple stress fluids and many authors [12-14] discussed the effect of couple stress lubricants on the characteristics of bearing systems. Combined effect of Magnetic field and couple stress lubricant was discussed by several researchers such as Kashinath and Hanumagowda [15] presented the composite slider bearing with MHD couple stress, and noticed due to magnetic field there is a increase in pressure, load carrying, frictional force and coefficient of friction. Hanumagowda et al [16-21] studied Land Tapered slider bearing and plane slider bearing, and Naduvinamani et al [22] discussed the effect of MHD couple stress on exponential slider bearings and noted that the increase in load carrying capacity. The aim of the current paper is to conduct a study on MHD Rayleigh step slider bearing lubricated with Couple-stress Fluids.

\section{THEORETICAL FORMULATION}

The physical configuration of the problem is shown in Figurelin which lower surface have pure tangential sliding motion relative to the other surface and separate by the lengths $L_{l}$ and $L_{2}$. The film thickness in the entry region is $h_{l}$ and in exit region is $h_{2}$. The uniform magnetic field $B_{0}$ is applied perpendicular to the two plates. The lubricant in the film region is incompressible. Stokes[7] couplestress fluid, body forces and body couples are assumed to be absent. The basic equations governing the hydro-magnetic flow of the lubricant in the fluid region are

$$
\begin{aligned}
& \mu \frac{\partial^{2} u}{\partial y^{2}}-\eta \frac{\partial^{4} u}{\partial y^{4}}-\sigma B_{0}^{2} u=\frac{\partial p}{\partial x}+\sigma E_{z} B_{0} \\
& \frac{\partial p}{\partial y}=0 \\
& \frac{\partial u}{\partial x}+\frac{\partial v}{\partial y}=0 \\
& \int_{y=0}^{h}\left(E_{z}+B_{0} u\right) d y=0
\end{aligned}
$$

From figure1 the boundary of the upper surface is given by

$$
h=\left\{\begin{array}{l}
h_{1} \text { for } 0 \leq x \leq L_{1} \\
h_{2} \text { for } L_{1} \leq x \leq L
\end{array} \quad \text { where } L_{1}+L_{2}=L\right.
$$




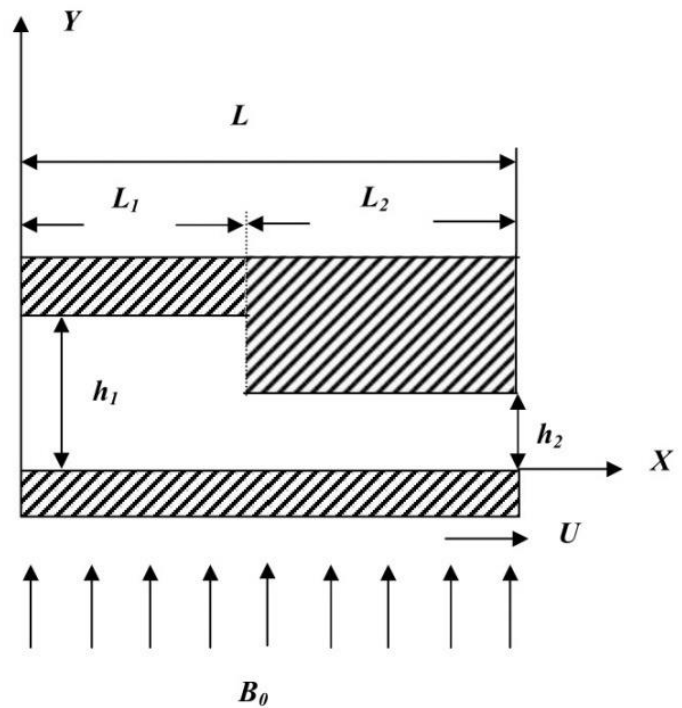

Figure1 Rayleigh step slider bearing

Boundary conditions are

At the upper surface $y=h$

$u=0 \frac{\partial^{2} u}{\partial y^{2}}=0 v=0$

At the lower surface $y=0$

$$
u=U \frac{\partial^{2} u}{\partial y^{2}}=0 \quad v=0
$$

Solution of equation (1) using condition (4) and the boundary conditions (5) and (6) is

$$
u=-\frac{h_{2}^{2} h}{2 l \mu M_{0}^{2}} \frac{\partial p}{\partial x}\left\{\frac{B^{2} \xi_{1}-A^{2} \xi_{2}}{\frac{B^{2}}{A} \tanh \left(\frac{A h}{2 l}\right)-\frac{A^{2}}{B} \tanh \left(\frac{B h}{2 l}\right)}\right\}-\frac{U}{2\left(A^{2}-B^{2}\right)}\left\{B^{2} \xi_{3}-A^{2} \xi_{4}\right\}
$$

where

$$
\begin{gathered}
\xi_{1}=\frac{\operatorname{Sinh} \frac{A h}{l}-\operatorname{Sinh} \frac{A y}{l}+\operatorname{Sinh} \frac{A(h-y)}{l}}{\operatorname{Sinh} \frac{A h}{l}}, \xi_{2}=\frac{\operatorname{Sinh} \frac{B h}{l}-\operatorname{Sinh} \frac{B y}{l}+\operatorname{Sinh} \frac{B(h-y)}{l}}{\operatorname{Sinh} \frac{B h}{l}}, \\
\xi_{3}=\frac{\operatorname{Sinh}\left(\frac{A h}{l}\right)-\operatorname{Sinh}\left(\frac{A y}{l}\right)-\operatorname{Sinh} \frac{A(h-y)}{l}}{\operatorname{Sinh}\left(\frac{A h}{l}\right)}, \xi_{4}=\frac{\operatorname{Sinh}\left(\frac{B h}{l}\right)-\operatorname{Sinh}\left(\frac{B y}{l}\right)-\operatorname{Sinh} \frac{B(h-y)}{l}}{\operatorname{Sinh}\left(\frac{B h}{l}\right)} .
\end{gathered}
$$

Integration of the continuity equation (3) over the film thickness with boundary conditions (5) and (6) results the modified Reynolds equation in the form 


$$
\frac{\partial}{\partial x}\left[\frac{6 h_{2}^{2} h^{2}}{\mu l M_{0}^{2}}\left\{\frac{A^{2}-B^{2}}{\frac{A^{2}}{B} \tanh \left(\frac{B h}{2 l}\right)-\frac{B^{2}}{A} \tanh \left(\frac{A h}{2 l}\right)}-\frac{2 l}{h}\right\} \frac{\partial p}{\partial x}\right]=6 U \frac{d h}{d x}
$$

Using the non-dimensional quantities, the non-dimensional MHD Reynolds-type equation is

$$
\frac{\partial}{\partial x^{*}}\left\{f\left(H, l^{*}, M_{0}\right) \frac{\partial P}{\partial x^{*}}\right\}=\frac{d H}{d x^{*}}
$$

where $f\left(H, l^{*}, M_{0}\right)=\frac{12 H^{2}}{l^{*} M_{0}^{2}}\left\{\frac{\left(A^{* 2}-B^{* 2}\right)}{\frac{A^{* 2}}{B^{*}} \tanh \left(\frac{B^{*} H}{l^{*}}\right)-\frac{B^{* 2}}{A^{*}} \tanh \left(\frac{A^{*} H}{l^{*}}\right)}-\frac{l^{*}}{H}\right\}$

$$
\begin{aligned}
& x^{*}=\frac{x}{L}, P=\frac{p h_{2}^{2}}{6 \mu U L}, l^{*}=\frac{2 l}{h_{2}}, \quad H=\frac{h}{h_{2}}, L_{1}^{*}=\frac{L_{1}}{L}, L_{2}^{*}=\frac{L_{2}}{L} \\
& A^{*}=\left[\frac{1+\left\{1-\left(l^{* 2} M_{0}^{2} / \mu\right)\right\}^{1 / 2}}{2}\right]^{1 / 2} \quad B^{*}=\left[\frac{1-\left\{1-\left(l^{* 2} M_{0}^{2} / \mu\right)\right\}^{1 / 2}}{2}\right]^{1 / 2}
\end{aligned}
$$

The relevant boundary conditions for pressure are

$$
P=0 \text { at } x^{*}=0,1
$$

Integrating both sides of equation (8) twice w.r.t. $x^{*}$ and using the boundary conditions (9) we get

$$
\begin{aligned}
& p_{1}^{*}=\frac{\left(h_{1}^{*}-1\right) L_{2}^{*} x^{*}}{L_{1}^{*} f^{*}\left(1, l^{*}, M_{0}\right)+L_{2}^{*} f^{*}\left(h_{1}^{*}, l^{*}, M_{0}\right)} 0 \leq x^{*} \leq L_{1}^{*} \\
& p_{2}^{*}=\frac{\left(h_{1}^{*}-1\right) L_{1}^{*}\left(1-x^{*}\right)}{L_{1}^{*} f^{*}\left(1, l^{*}, M_{0}\right)+L_{2}^{*} f^{*}\left(h_{1}^{*}, l^{*}, M_{0}\right)} L_{1}^{*} \leq x^{*} \leq 1
\end{aligned}
$$

The non-dimensional load carrying capacity is

$$
W^{*}=\frac{W h_{2}^{2}}{6 \mu U L^{2}}=\int_{0}^{L_{1}^{*}} P_{1}^{*} d x^{*}+\int_{L_{1}^{*}}^{1} P_{2}^{*} d x^{*}
$$

Using (10a) and (10b) the non dimensional load carrying capacity is obtained in the form

$$
W^{*}=\frac{\left(h_{1}^{*}-1\right) L_{1}^{*} L_{2}^{*}}{2\left\{L_{2}^{*} f^{*}\left(h_{1}^{*}, l^{*}, M_{0}\right)+L_{1}^{*} f^{*}\left(1, l^{*}, M_{0}\right)\right\}}
$$

The components of stress tensor required for calculating frictional forceis

$$
\left.\tau_{y x}\right|_{y=0}=\mu \frac{\partial u}{\partial y}-\eta \frac{\partial^{3} u}{\partial y^{3}}
$$


The frictional force on the bearing surface is

$$
F=\int_{0}^{L}\left[-\frac{\mu U l M_{0}^{2}}{2 h_{2}^{2}\left(A^{2}-B^{2}\right)}\left\{\frac{A^{2}}{B} \operatorname{coth}\left(\frac{B h}{2 l}\right)-\frac{B^{2}}{A} \operatorname{coth}\left(\frac{A h}{2 l}\right)\right\}-\frac{h}{2} \frac{\partial p}{\partial x}\right] d x
$$

The dimension less frictional force is

$$
\begin{aligned}
& \begin{array}{l}
F^{*}=-\frac{F h_{2}}{6 \mu U L} \\
=G\left(h_{1}^{*}, l^{*}, M_{0}\right) L_{1}^{*}+G\left(1, l^{*}, M_{0}\right) L_{2}^{*} \\
\quad+\frac{\left(h_{1}^{*}-1\right)^{2} L_{1}^{*} L_{2}^{*}}{2\left\{f\left(1, l^{*}, M_{0}\right) L_{1}^{*}+f\left(h_{1}^{*}, l^{*}, M_{0}\right) L_{2}^{*}\right\}} \\
\text { where } G\left(h_{1}^{*}, l^{*}, M_{0}\right)=\frac{l^{*} M_{0}^{2}}{24\left(A^{* 2}-B^{* 2}\right)}\left\{\frac{A^{* 2}}{B^{*}} \operatorname{coth}\left(\frac{B^{*} h_{1}^{*}}{l^{*}}\right)-\frac{B^{* 2}}{A^{*}} \operatorname{coth}\left(\frac{A^{*} h_{1}^{*}}{l^{*}}\right)\right\} \\
G\left(1, l^{*}, M_{0}\right)=\frac{l^{*} M_{0}^{2}}{24\left(A^{* 2}-B^{* 2}\right)}\left\{\frac{A^{* 2}}{B^{*}} \operatorname{coth}\left(\frac{B^{*}}{l^{*}}\right)-\frac{B^{* 2}}{A^{*}} \operatorname{coth}\left(\frac{A^{*}}{l^{*}}\right)\right\}
\end{array}
\end{aligned}
$$

The co-efficient of friction is given by

$$
C=\frac{F^{*}}{W^{*}}
$$

\section{Limiting case of the Present Study}

As $M_{0} \rightarrow 0$ equations (11), (12) and (13) reduces to the case studied by Ramanaiah and Sarkar[8](case2.1). The comparison of present analysis with Ramanaiah and Sarkar[8] is given in table1.

\section{RESULTSANDDISCUSSIONS}

The effect of MHD on Rayleigh step slider bearing lubricated with couplestress fluids is studied. The results are discussed for various non-dimensional parameters namely Hartmann number $M_{0}$, couple-stress parameter $l^{*}$, bearing length $L_{1}^{*}$ as follows.

\section{Pressure}

Figures 2 shows the variation of non-dimensional pressure $P^{*}$ with $x$ *for distinct values of $M_{0}$ and $l^{*}$ with fixed values $L_{1}^{*}=0.7, h_{1}{ }^{*}=2$. It is observed that the pressure increases with increasing values of Hartmann number $M_{0}$ and couplestress parameter $l^{*}$ as compared with Non-magnetic case and Newtonian case. The deviation of non-dimensional pressure $P^{*}{ }_{\text {max }}$ with $L_{1}^{*}$ as function of $M_{0}$ and $l^{*}$ with fixed values $h_{l}{ }^{*}=2$ is depicted in Figures3. It is found that pressure is maximum for $L_{1}^{*}$ lies between 0.7 and 0.8 . 

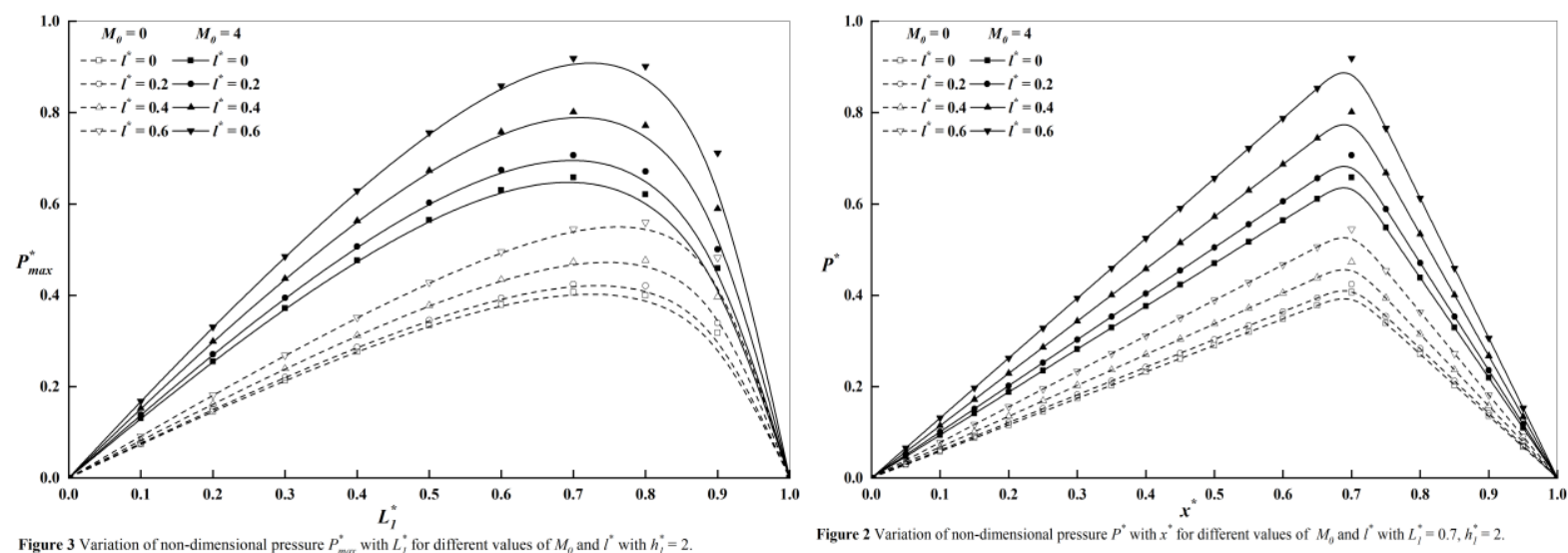

\section{Load Carrying Capacity}

Figures4 shows the variation of non-dimensional load carrying capacity $W^{*}$ with step height $h_{l}{ }^{*}$ for various values of $M_{0}$ and $l^{*}$ with fixed values $L_{1}^{*}=0.7$. It is observed that the effect of Hartmann number $M_{0}$ and couple stress parameter $l^{*}$, increases load carrying capacity. The non-dimensional load increases with $h_{l}{ }^{*}$ until a maximum is obtained, and there after decreases with $h_{l}{ }^{*}$. In Figure5 the graph of non-dimensional load carrying capacity $W^{*}$ with $L_{1}^{*}$ for different values of $M_{0}$ and $l^{*}$ with fixed values $h_{1}{ }^{*}=2$ is plotted and observed that maximum load carrying capacity is for $L_{1}^{*}$ lies in the interval 0.7 and 0.8 .

Table 1: Present analysis is compared with work done by Ramanaiah and sarkar [8] by varying MHD and couple stress parameter and values are tabulated for $W^{*}, F^{*}, C$ and with $L_{1}{ }^{*}=0.5$.

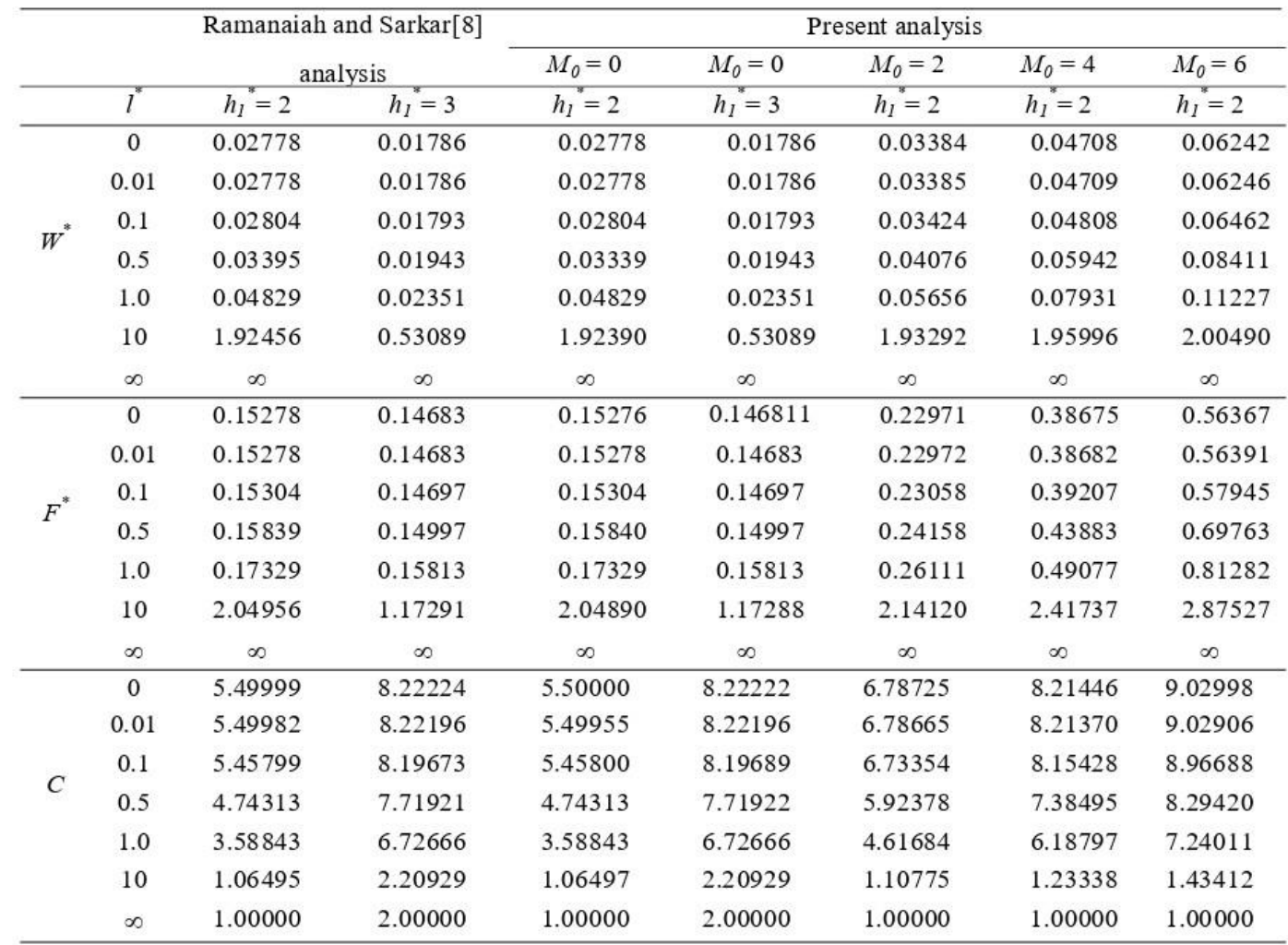




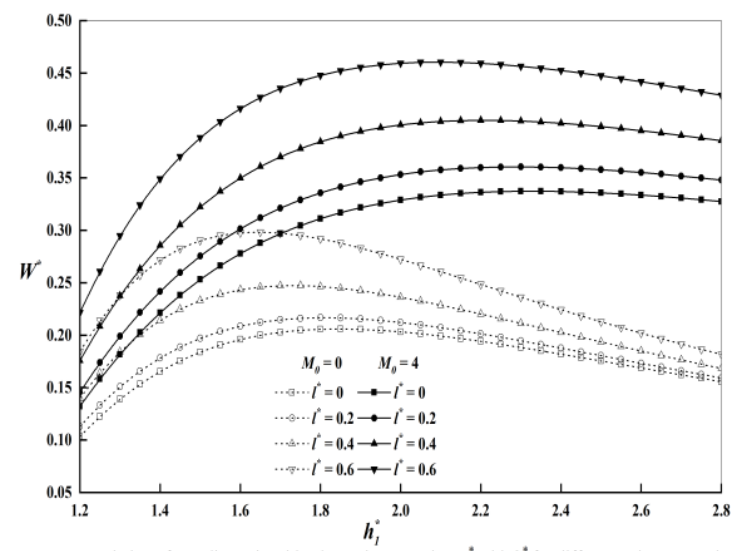

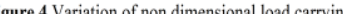
$l^{*}$ with $L_{l}^{*}=0.7$.

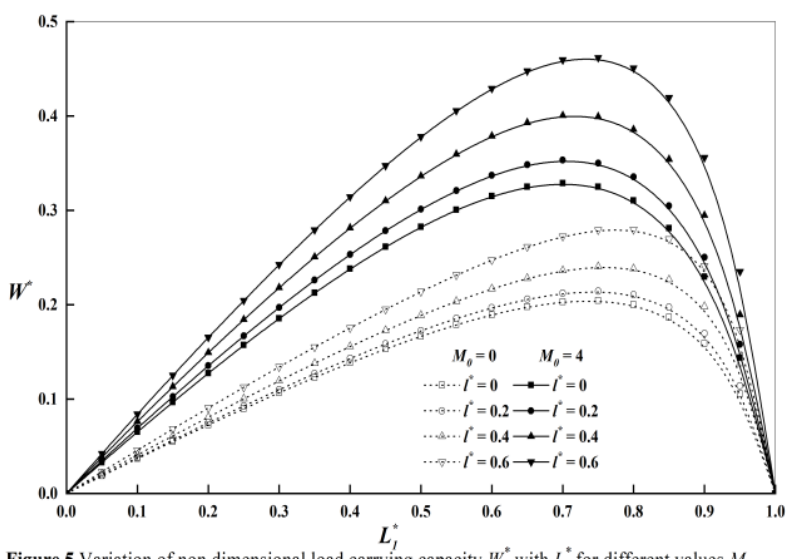

and $l^{*}$ with $h_{1}^{*}=2$

\section{Frictional Force}

Figure6 displays the variation of non-dimensional frictional force $F^{*}$ with step height $h_{1}{ }^{*}$ for different values of $M_{0}$ and $l^{*}$ with fixed values $L_{l}{ }^{*}=0.7$. It is observed that frictional force increases with increasing values of $M_{0}$ and $l^{*}$ as compared with Non-magnetic case and Newtonian case. For the bearing with a Non-magnetic lubricant the frictional force decreases with increasing value of the step height $h_{l}{ }^{*}$ and the bearing with a magnetic lubricant the frictional force increases with increasing value of the step height $h_{l}{ }^{*}$. Figure7 shows the variation of non-dimensional frictional force $F^{*}$ with $L_{l}{ }^{*}$ for different values of $M_{0}$ and $l^{*}$ with fixed values $h_{l}{ }^{*}=2$. It is seen that frictional force decreases with an increase of $L_{l}{ }^{*}$ for nonmagnetic case and for magnetic case frictional force increases with anincrease of $L_{l}{ }^{*}$ until a maximum is obtained, and there after decreases with $L_{l}{ }^{*}$.

\section{Coefficient of Friction}

Figure8 shows the variation of coefficient of friction $C$ with step height $h_{l}{ }^{*}$ for different values of $M_{0}$ and $l^{*}$ with fixed values $L_{l}{ }^{*}=0.7$. It is observed that coefficient of friction increases with an increase in Hartmann number $M_{0}$ and decreases due to increase in couplestress parameter $l^{*}$. Figure9 depicts, the deviation of coefficient of friction $C$ with $L_{l}{ }^{*}$ for different values of $M_{0}$ and $l^{*}$ with fixed values $h_{l}{ }^{*}=2$. It is noted that the coefficient of friction $C$ decreases with $L_{l}{ }^{*}$ until a minimum is obtained, and there after increases with $L_{l}{ }^{*}$.

The relative percentage increase in the non-dimensional load carrying capacity $R_{W}{ }^{*}$, non-dimensional frictional force $R_{F}{ }^{*}$ and coefficient of friction $R_{C}$ are defined by

$$
\begin{aligned}
& R_{W^{*}}=\left\{\left(W_{\text {magnetic }}^{*}-W_{\text {non-magnetic }}^{*}\right) / W_{\text {non-magnetic }}^{*}\right\} \times 100 R_{F^{*}}=\left\{\left(F_{\text {magnetic }}^{*}-F_{\text {non-magnetic }}^{*}\right) / F_{\text {non-magnetic }}^{*}\right\} \times 100 \\
& \text { and } R_{C}=\left\{\left(C_{\text {magnetic }}-C_{\text {non-magnetic }}\right) / C_{\text {non-magnetic }}\right\} \times 100
\end{aligned}
$$

The values of $R_{W}{ }^{*}, R_{F}{ }^{*}$ and $R_{C}$ are listed in Table2 for various values of $l^{*}, M_{0}$ with $L_{l}{ }^{*}=0.7, h_{I}{ }^{*}=2$. It is clear that an increase of nearly $66.43 \%, 185 \%$ and $71.23 \%$ in $W^{*}, F^{*}$ and $C$ is observed for $l^{*}=0.2$ and $M_{0}=4$. 


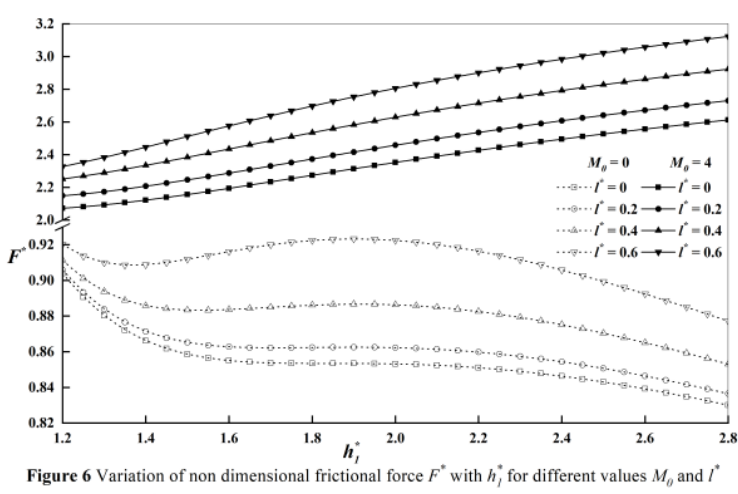
with $L_{i}^{*}=0.7$.

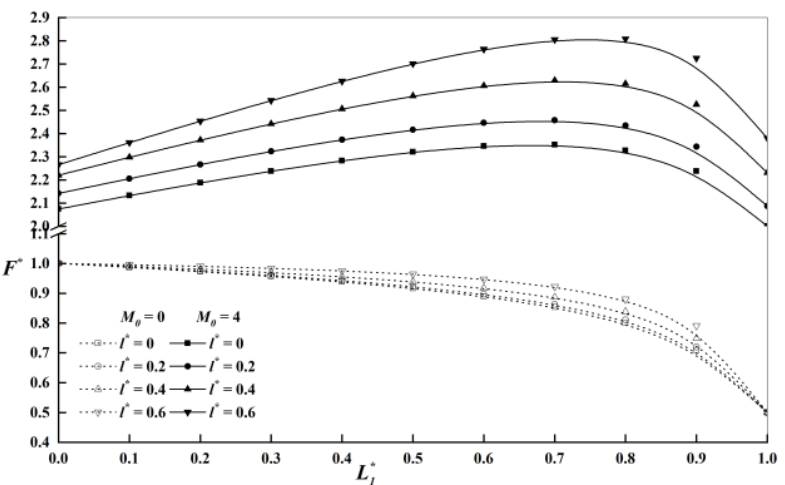

Figure 7 Variation of non dimensional frictional force $F^{*}$ with $L_{j}^{*}$ for different values $M_{0}$ and $l^{*}$ with $h_{l}^{*}=2$.

\section{CONCLUSIONS}

Using the continuity equation and the MHD motion equations the characteristics of Rayleigh step slider bearings with an electrically conducting fluid in the presence of a transverse magnetic field are investigated. According to the results and discussion, conclusions can be drawn as follows.

- The Pressure, load carrying capacity, frictional force and coefficient of friction of Rayleigh step slider bearing is significant for larger values of couples tress parameter $l^{*}$ as compared to Newtonian case.

- The applied magnetic field increases the load carrying capacity, the frictional force and the coefficient of friction as compared with the corresponding non-magnetic case.

- The relative load $R_{W^{*}}$, the relative frictional force $R_{F}{ }^{*}$ and the relative coefficient of friction $R_{C}$ increases with increasing values $M_{0}$, an increase of about $66.43 \%$ in $W^{*}, 184.97 \%$ in $F^{*}$ and $71.23 \%$ in $C$ is observed for $l^{*}=0.2$ and $M_{0}=4$.

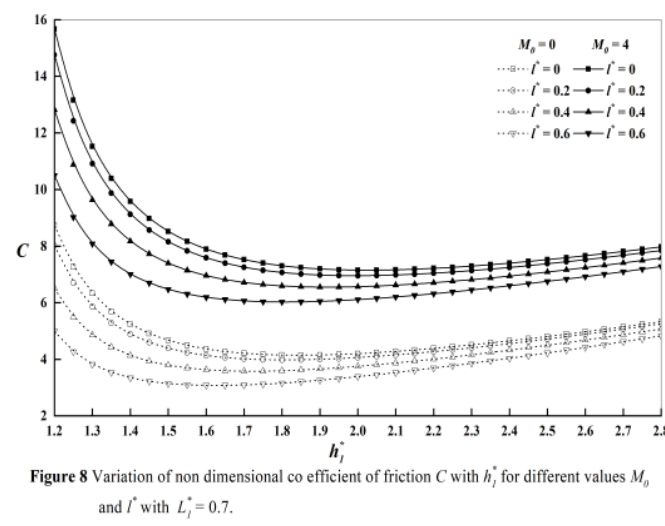

NumericalexampleofRayleighstepsliderbearingwithMHDandcouplestressisgivenintable3. 
Table2: Variation of $R_{W}{ }^{*}, R_{F}{ }^{*}$ and $R_{C}$ for different values $l^{*}$ and $M_{0}$ with $L_{l}{ }^{*}=0.7, h_{l}^{*}=2$.

\begin{tabular}{ccrrr}
\hline$l^{*}$ & $M_{0}$ & \multicolumn{1}{c}{$R_{W}^{*}$} & \multicolumn{1}{c}{$R_{F}^{*}$} & \multicolumn{1}{c}{$R_{C}$} \\
\hline \multirow{2}{*}{0} & 2 & 19.62295 & 59.77411 & 33.56485 \\
& 4 & 61.86164 & 175.7124 & 70.33877 \\
& 6 & 110.8811 & 302.3946 & 90.81629 \\
\hline \multirow{2}{*}{0.2} & 2 & 20.31353 & 60.6829 & 33.55357 \\
& 4 & 66.42942 & 184.9719 & 71.22706 \\
& 6 & 123.4867 & 330.3289 & 92.55259 \\
\hline \multirow{2}{*}{0.4} & 2 & 20.47991 & 61.57736 & 34.11076 \\
& 4 & 69.50104 & 196.5752 & 74.96881 \\
& 6 & 132.3145 & 363.4397 & 99.48705 \\
\hline \multirow{2}{*}{0.6} & 2 & 19.5771 & 61.44175 & 35.0109 \\
& 4 & 68.58107 & 204.0893 & 80.38196 \\
& 6 & 132.9851 & 386.3871 & 108.7643 \\
\hline
\end{tabular}

Table 3: Numerical example of Rayleigh step slider bearing with MHD and couple-stress fluid

\begin{tabular}{lcc}
\hline \multicolumn{1}{c}{ Physical parameter } & Notation & Range of values chosen \\
\hline Length of the bearing & $L$ & $1.0 \times 10^{-1} \mathrm{~m}$ \\
Minimum film thickness & $h_{2}$ & $0.5 \times 10^{-4} \mathrm{~m}$ \\
Maximum film thickness & $h_{l}$ & $(0.6$ to 1.4$) \times 10^{-4} \mathrm{~m}$ \\
Electrical conductivity & $\sigma$ & $1.07 \times 10^{6} \mathrm{mh}_{0} / \mathrm{m}$ \\
Applied magnetic field & $B_{0}$ & $0,1.52,3.04,4.56 \mathrm{~Wb} / \mathrm{m}^{2}$ \\
Lubricant viscosity & $\mu$ & $1.55 \times 10^{-3} \mathrm{~Pa} . \mathrm{S}$ \\
Couple stress material & $\eta$ & $0,0.3875,1.55,6.2 \times 10^{-13} \mathrm{~N} . \mathrm{s}$ \\
\hline
\end{tabular}

\section{REFERENCES}

1. Snyder W. T. The magnetohydrodynamic slider bearing, Journal of Basic Engineering, 84, (1962),197.

2. Shukla J. B. The optimumone-dimensional magnetohydrodynamic slider bearing, Journal of tribology, 92(3), (1970),530

3. Hughes W. F. The magnetohydrodynamic finite step slider bearing, Journal of Basic Engineering, 85, (1963), 129.

4. Anwar M. I. and Rodkiewicz C. M. Solution for MHD slider bearing with arbitrary magnetic field, ASME J lubrication technology, 94, (1972), 288.

5. W. Jianming and J. Gaobing, "The optimal design of the Reyleigh slider bearings with a power law fluid. Wear, Vol 129, pp.1-11, 1989.

6. N. B. Naduvinamani and A. Siddangouda, “A note on porous Rayleigh step bearing Lubricated with couplestress fluids”, Journal of Engineering Tribology, Vol 221, pp. 615-621, 2007.

7. V. K. Stokes, “Couplestresses in fluids”, Physics of Fluids, Vol9, pp.1709, 1966.

8. G. Ramanaiah, P. Sarkar, “Slider bearing lubricated by fluids with couple-stress”, Wear; Vol. 52, pp.27-36,1979.

9. Oladeinde, Mobolaji H. Akpobi, A. John., "Performance of Infinitely wide parabolic and inclined slider bearing lubricated with couplestress or magnetic fluids ,Proceedings on world congress on engineering, Vol.1394, pp.58-68, 2011.

10. N. B. Naduvinamani, S. T. Fathima and P. S. Hiremath, "Hydrodynamic lubrication of rough slider bearings with couplestress fluid”, Tribology International, Vol 36(2), pp.949-959,2003.

11. N. M. Bujurke, N. B. Naduvinamani and M. Jagadeeshwar, "Porous Rayleigh step slider bearing with second orderfluid", ZAMM, Vol 70 (11), pp.517-526,1990.

12. J. R. Lin, R. F. Lu, "Derivation of dynamic couplestress Reynolds equation sliding-squeezing surfaces and numerical solution of plane inclined slider bearings", Tribology International, Vol 36(9), pp.679-685,2003.

13. Lin, Chu and Liaw, "Effects of non-newtonian couplestress on the dynamic characteristics of wide reyleigh step slider bearings", Journal of Marine Science and Technology, Vol 20(5), pp. 547-553, 2012.

14. R. Rahmani, J. Shrivani and H. Shirvani, “Analytical analysis of optimization of Rayleighstep slider bearing”, Tribology International, Vol 42(5), pp. 666-674, 2009.

15. Biradar kashinath and B. N. Hanumagowda, "MHD effect on composite slider bearing with couplestress fluid," 
International Journal of Mathematics Trends and Technology,Vol5, pp.27-49, 2004.

16. B. N. Hanumagowda, T. Gonchigara, J. Santhosh kumar and H. Shivakumar, "Steady and dynamic characteristics of MHD land-Tapered slider bearing with couplestress model", International Journal of Pure and Applied Mathematics,Vol113(6), pp.325-333, 2017.

17. B. N. Hanumagowda, "Effect of magnetohydrodynamic and couplestress on steady and dynamic characteristics of plane slider bearings", Tribology Online, Vol 11(1), 40-49,2016.

18. Al-Ansari, Luays. "Calculating static deflection and natural frequency of stepped cantilever beam using modified Rayleigh method. "International Journal of Mechanical and Production Engineering Research and Development (IJMPERD)Vol. 3.4(2013):pp. 107-118.

19. Kumaran, S. Jaya Vasantha, and S. Hari Prashaant."Performance Analysis of Cyclic Prefix Based Mobile Broadband Wireless Access System with Various Modulation Techniques. "Development(IJECIERD),Vol. 3.2(2013):pp. 117-122.

20. Patil, Sunil, and Rupali Satpute."Performance Evaluation of Antennas for Enhancing Ergodic Capacity of Channel in Wireless Communication. "International Journal of Electrical and Electronics Engineering Research(IJEEER))(2016).

21. Subramanium, Priti, and Rajeshree D.Raut. "Performance Analysis of Turbo Coded OFDM: Subjected to Different Channels. International Journal of Computer Science Engineering and Information Technology Research(IJCSEITR), Vol. 4.1(2014):pp. 25-34.

22. N. B. Naduvinamani, A. Siddangouda and Siddharam P, "Effect of magnetohydrodynamic couplestress on dynamic characteristics of exponential slider bearing”, Tribology in Industry, Vol39(1),pp.31-44,2017. 


\section{AUTHORSPROFILE}

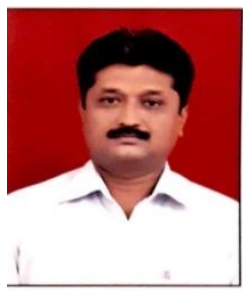

Dr. Ayyappa G. Hiremath is working as Assoc. Professor in the Department of Mathematics, P D A College of Engineering, Kalaburagi. He obtained M.sc in Mathematics from Gulbarga University, Kalaburagi and doctoral degree from Gulbarga University Kalaburagi, India in area of Fluid Dynamics. He has 26 years of teaching experience. He has published 09 research articles in National and International journals. His area of interest includes Differential Equations, Fluid Dynamics and MHD.

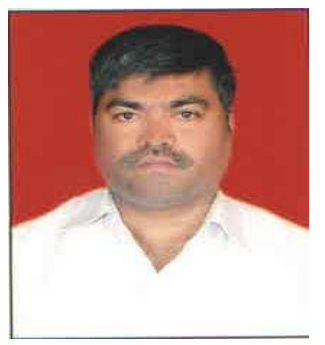

Dr. Hanumagowda B. N. is working as Professor in the Department of Mathematics, School of Applied Sciences, REVA University, Bengaluru. He obtained M. Sc from Mathematics by Karnataka University, Dharwad and doctoral degree from Gulbarga University, Gulbarga, India in the area of Fluid Dynamics. He has 31 years of teaching experience. He has published 64 research articles in National and International journals. His area of interest includes Differential Equations, Fluid Dynamics, Mathematical Modeling and MHD.

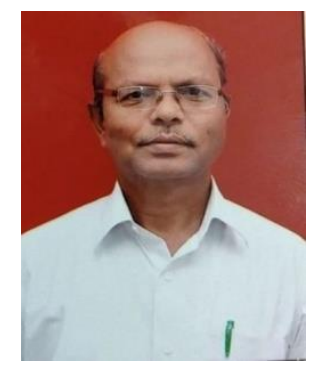

Dr. Biradar Kashinath is working as Professor and Principal in the Department of Mathematics, Govt. First Grade College, Aland. He obtained M.sc in Mathematics from Gulbarga University, Kalaburagi and doctoral degree from Gulbarga University Kalaburagi, India in area of Fluid Mechanics. He has 35 years of teaching experience. He has published 08 research articles in National and International journals. His area of interest includes Lubrication Theory, Fluid Dynamics and MHD. 


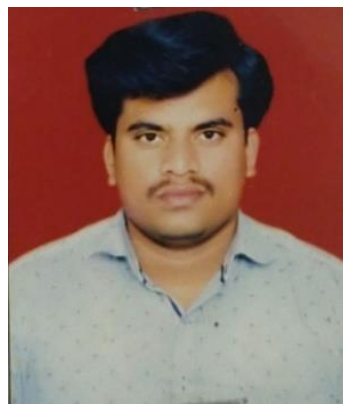

Dhanraj Neela is working as Asst. Professor in the Department of Mathematics, Faculty of Engineering and Technology (Co-Ed), Sharnbasva University, Kalaburagi. He obtained M.sc in Mathematics from Gulbarga University, Kalaburagi and Persuing doctoral degree from Visveswaraya Technological University, Belagavi, India in area of Fluid Dynamics. He has 06 years of teaching experience. His area of interest includes Fluid Dynamics, Differential Equations and MHD. 